\title{
Mineração
}

\section{Movimentos em encostas de Ouro Preto, MG - o caso da Vila São José}

\author{
Sueli Batista Ferreira \\ Mestranda do Programa de Pós-Graduação em Engenharia Mineral \\ E-mail:suelibferreira@ibest.com.br \\ Milene Sabino Lana \\ Professora Adjunta do Departamento de Engenharia de Minas/UFOP \\ E-mail:milene@demin.ufop.br \\ Artur Antônio Conte Jr. \\ Aluno do Departamento de Engenharia de Minas/UFOP \\ E-mail:arturconte@yahoo.com.br \\ Leonardo de Freitas Leite \\ Aluno do Departamento de Engenharia de Minas/UFOP \\ E-mail:Ifleonardo@yahoo.com.br
}

\section{Resumo}

Esse trabalho discute os movimentos em encostas de Ouro Preto, a partir de um exemplo envolvendo um escorregamento em talude no Morro do Curral, localizado na Vila São José. Alerta-se acerca dos riscos de movimentos devido à inadequada ocupação urbana na base da encosta, enfatizando o problema da ação antrópica e suas conseqüências na reincidência de movimentos. A ação do intemperismo químico no comportamento do material rochoso é discutida. Um levantamento preciso do escorregamento em campo é apresentado, mostrando a geometria da superfície de ruptura. O levantamento de campo permitiu a exata reconstituição da superfície de ruptura.

Palavras-chave: Escorregamentos, expansão urbana, Morro do Curral.

\begin{abstract}
In this work the landslides in Ouro Preto have been discussed through an example involving a landslide in a slope at Morro do Curral, situated in Vila São José. The risks of landslides due to the inadequate urban expansion at the base of the hill have been presented, pointing out the problem of the comeback of movements. The effect of chemical weathering on the rock mass behavior has been discussed. A precise field survey of the landslide has been presented, showing the geometry of the failure surface. The field survey allowed the exact reconstitution of the failure surface.
\end{abstract}

Keywords: Landslides, urban expansion, Morro do Curral hill. 


\section{Introdução}

Os movimentos em encostas têm grande impacto na ocupação das cidades em geral, principalmente para aquelas que se encontram encravadas nos flancos de serras e montanhas.

No Brasil, várias são as cidades e zonas metropolitanas que apresentam histórico de ocorrência de movimentos de massa, com vítimas fatais e danos materiais decorrentes. Ouro Preto é uma das prejudicadas nesse aspecto. Características morfológicas, climáticas e geológicas, o relevo forte e o alto índice pluviométrico, entre outros fatores, predispõem movimentos de massa e processos erosivos nas formações rochosas de Ouro Preto. O Morro do Curral está situado no centro histórico da cidade de Ouro Preto. Estende-se desde o bairro Jardim Alvorada, divisando com o bairro Vila São José, praça Rio Branco até a praça Cesário Alvim, onde se localiza o prédio da antiga estação ferroviária.

$\mathrm{Na}$ área objeto de estudo desse trabalho, no Morro do Curral, existe um histórico de ocorrência de movimentos de massa importantes e a situação atual aponta para riscos iminentes de movimentos, que podem ocasionar acidentes até fatais e grandes prejuízos ao patrimônio histórico da cidade.

Morfologicamente, a encosta tem inclinação média de $45^{\circ}$, altura da ordem de $50 \mathrm{~m}$, comprimento na base de $151 \mathrm{~m}$. Apresenta perfil irregular, com escarpas quase verticais e aproximadamente paralelas, vertentes irregulares, com declives variáveis. Apresenta, no seu topo, uma cobertura vegetal rasteira. A drenagem é representada por dois talvegues principais (Fernandes, 2002).

O talude estudado localiza-se na Vila São José, final da Rua Albino Sartori. Não obstante ter sido feito o retaludamento da área no passado, em função de movimentos de massa ocorridos em 1979, hoje já se observam novos escorregamentos e expressiva ocupação urbana, embora, na época das obras de retaludamento, houvesse preocupação em inibir a construção de residências na base da encosta.

Um escorregamento justamente na área do retaludamento foi estudado neste trabalho. A geometria da superfície de ruptura foi mapeada através de levantamento topográfico de detalhe e o material que constitui o talude foi descrito em termos de composição mineralógica e resistência mecânica.

Estudos anteriores no Morro do Curral mostram a ocorrência de escorregamentos condicionados por superfícies de descontinuidades, embora na mesma litologia esse estudo indicou a ocorrência de um escorregamento aproximadamente circular com um padrão distinto dos estudos anteriores. Isso indica grande variedade de movimentos ocorrentes na encosta e vem reforçar a importância de estudos de estabilidade no local.

\section{Histórico de escorregamentos na área estudada}

As fortes chuvas de dezembro de 1978 a fevereiro de 1979 fizeram com que fosse deflagrada uma série de escorregamentos em Ouro Preto; o pior e maior deles ocorreu na Vila São José, onde sua encosta foi atingida por fendas em toda sua extensão (Figura 1), culminando em deslocar um volume de aproximadamente $100.000 \mathrm{~m}^{3}$ de material. O escorregamento se deu no xisto do Grupo Sabará e foi causado pela erosão da base da encosta, onde aflorava o quartzito Taboões bem alterado e friável (Sobreira et al., 1990).

A ocorrência extensiva de tais movimentos de massa deu início a um dos maiores trabalhos geotécnicos de Ouro Preto: o retaludamento da encosta na vila.

O projeto de suavização da encosta foi elaborado pela Tecnosolo, sob a orientação do Prof. A. J. Costa Nunes, sua organização e execução tiveram também a participação da Secretaria de Planejamento - SEPLAN-MG, Departamen- to de Estradas e Rodagem - DER-MG, Universidade Federal de Ouro Preto UFOP, Instituto Estadual do Patrimônio Histórico e Artístico - IEPHA, Instituto do Patrimônio Histórico e Artístico Nacional - IPHAN, Prefeitura Municipal de Ouro Preto - PMOP, Combe Construtora Imbé S.A., Companhia de Pesquisa de Recursos Minerais - CPRM, e assessoria das Minerações Brasileiras Reunidas -MBR.

Decidiu-se à época pela suavização da encosta, com a remoção de $600.000 \mathrm{~m}^{3}$ de material que foi colocado sobre o antigo depósito de efluentes da Alcan Alumínio do Brasil, depósito inativo conhecido como "lago de lama", com área de $100.000 \mathrm{~m}^{2}$, situado à montante da rua Dr. Horlando Ramos. Essa alternativa, além de ser de menor custo, evitava a remoção do material deslizado por dentro do centro da cidade, em função do curto percurso entre as obras e a área de deposição. O trânsito de caminhões carregados de material pelo centro histórico acarretaria danos ao conjunto do núcleo histórico de Ouro Preto.

A conformação geométrica na base do talude deveria funcionar como área de segurança quanto a possíveis escorregamentos no futuro. Os técnicos recomendaram a construção de um tapume por cerca de arame, contornando os limites inferiores da área de terraplenagem, para inibir a ocupação de tipo permanente, como moradia ou outras edificações; recomendaram também a instalação de um completo sistema de drenagem e a cobertura vegetal com grama em todos os taludes. Quanto ao uso futuro, a medida adotada deveria ser a implantação de um bosque de árvores de porte médio (ou pomar), a fim de reforçar a estabilidade do terreno e diluir a agressividade visual da obra. Um ano mais tarde, em junho de 1980, constatou-se que alguns trechos evidenciavam a reativação de antigos escorregamentos, em virtude da não implantação do sistema de drenagem previsto; a falta da drenagem proporcionou uma maior deterioração de parte dos taludes e banquetas, tendo, inclusive, merecido a remodelação de parte da obra. 


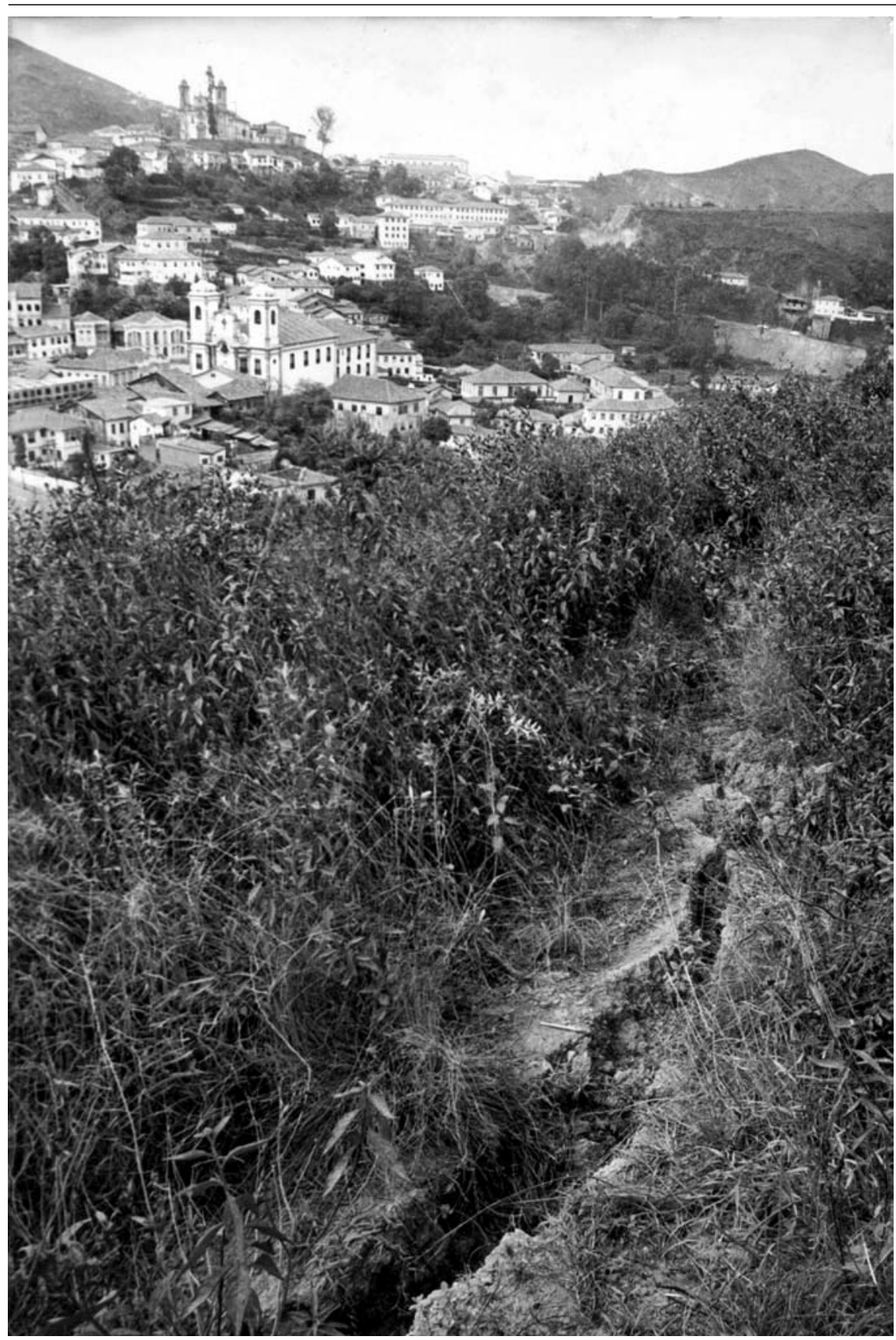

Figura 1 - Detalhe de fenda observada na encosta à montante da Rua Dr. Horlando Ramos (Fonte: IPHAN).

Bonuccelli (1999) fez um levantamento, junto ao corpo de bombeiros, relativo aos movimentos gravitacionais de massa e processos associados. Das 488 ocorrências registradas pelo corpo de bombeiros na área urbana de Ouro Preto, entre 1988 e 1998, cinco delas foram na Vila São José. Destas, quatro foram registradas na rua Dr. Albino Sartori, referentes a escorregamentos e inundações - em novembro de 1989, fevereiro de 1992, ções importantes, como as instalações do Centro de Convenções e Artes de Ouro Preto, residências, restaurante, farmácias, padaria, Escola Estadual Dom Velloso etc. Problemas advindos da desestabilização da encosta podem ter graves conseqüências, o que ensejou a realização de estudos anteriores envolvendo problemas de ruptura observados em diferentes locais na base da encosta. Além disso, a encosta localiza-se no centro histórico de Ouro Preto, podendo ser vista de diversos locais da cidade, vários deles pontos turísticos importantes, o que provoca grande impacto visual numa cidade que é patrimônio histórico mundial.

Pinheiro et al. (2003) fazem considerações acerca da influência da expansão urbana nos movimentos ocorridos no Morro do Curral, chamando a atenção para o descaso dos órgãos fiscalizadores e salientando a importância da realização de trabalhos voltados à geração de dados acerca das características dos terrenos, que, como também salientado por Fernandes (2000), são pouco conhecidas.

Hoje, a encosta da Vila São José, apesar das obras de drenagem e de todo o trabalho de suavização realizado na área, em função do tempo e das chuvas, conjuntamente com a falta de monitoramento e fiscalização, é foco de uma nova preocupação devido à expressiva ocupação na área do retaludamento (Figura 2).

A urbanização, que ocorre de forma desordenada, foi incorporada como uma expansão natural da vila, face à falta de fiscalização, com métodos inadequados de construção e desconhecimento dos riscos desses métodos, Figura 2. Ameaças para Ouro Preto não faltam e, no Morro do Curral - Vila São José -, o perigo dos deslizamentos de terra, em épocas de chuva, coloca em risco um grande número de residências. 


\section{Apresentação dos resultados}

\subsection{Mineralogia e estado de alteração do material rochoso}

O maciço rochoso do Morro do Curral pertence ao Grupo Sabará, Supergrupo Minas, composto de filitos, xistos, grauvacas, subgrauvacas, tufos metamorfoseados e formação ferrífera. Os litotipos presentes são quartzo-cloritasericita-xisto, biotita-xisto e outros, originados pela variação de metamorfismo (Dorr, 1969).

O material do talude estudado encontra-se muito alterado, apresentando uma decomposição não uniforme. Em alguns locais da encosta no Morro do Curral, ocorrem descontinuidades que apresentam efeitos nítidos de intemperismo, com intensa decomposição. O xisto do talude escolhido desagrega-se parcialmente na presença de água e quebrase facilmente com choque mecânico. Em alguns pontos do talude, apresenta-se totalmente friável. A cor varia de ocre a marrom, chegando a ficar cinza em alguns trechos, e, nos locais mais alterados, tem-se uma coloração de marrom a avermelhada.

Nos problemas de engenharia, é conveniente que rochas de resistência muito baixa que se apresentem muito intemperizadas sejam tratadas como solos para efeito da sua caracterização física e obtenção de parâmetros de resistência. Tal é o caso do maciço rochoso do Morro do Curral, na área de estudo desse trabalho. Ferreira (2004) encontrou, através de ensaios de laboratório, valores de coesão variando de 0 a $19 \mathrm{kPa}$ e ângulo de atrito na faixa $19 \mathrm{a}$ $28^{\circ}$. Os valores de coesão encontrados são muito diferentes daqueles apresentados por Hunt (1984) para xistos alterados e bem mais próximos de materiais caracterizados como saprolitos por esse mesmo autor.

Foi feita a análise de RX para uma identificação qualitativa dos componentes mineralógicos presentes no xisto. Os resultados mostram a presença de quartzo, mica muscovita e ocorrência do argilomineral caulinita (Figura 3).

Também foram feitas lâminas delgadas para caracterização mineralógica. O quartzo é o principal mineral constituinte da rocha analisada, é concordante com a xistosidade, está orientado e localmente dobrado; seguido da presença de micas, sericita e muscovita (Figura 4).

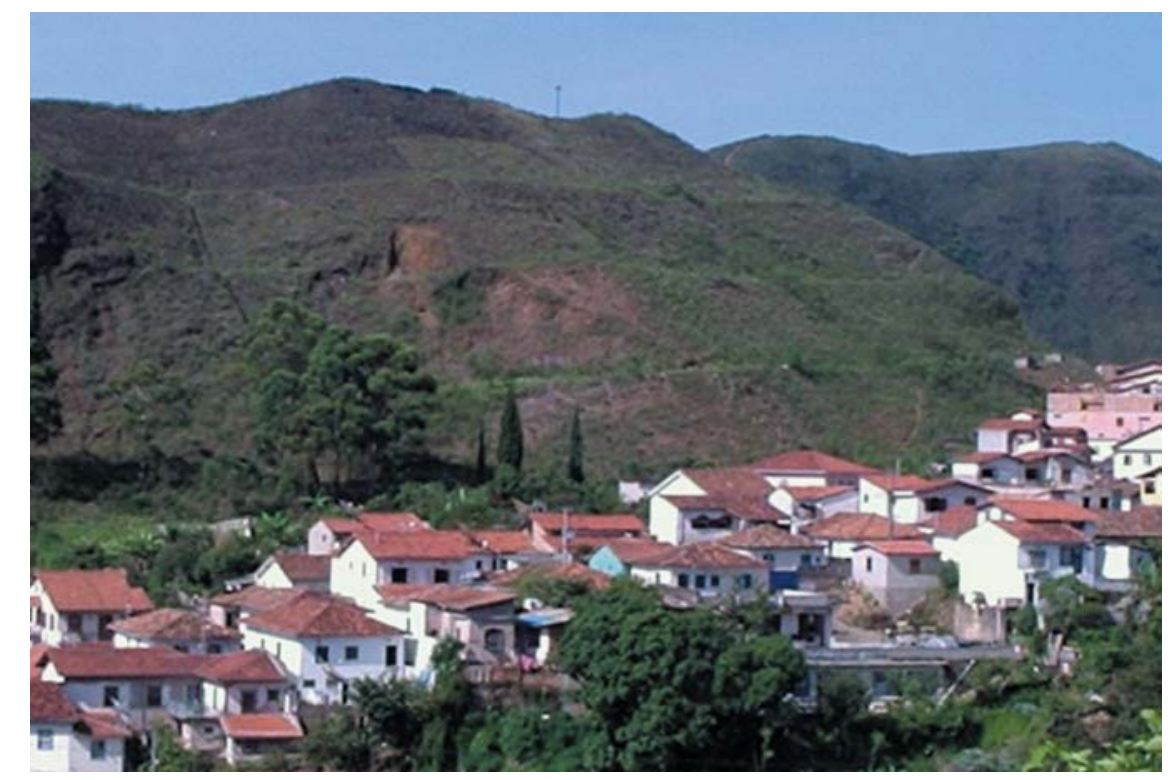

Figura 2 - Residências próximas da encosta, Vila São José; observar o escorregamento

Figura 2 - Residências próxim
na área do retaludamento.

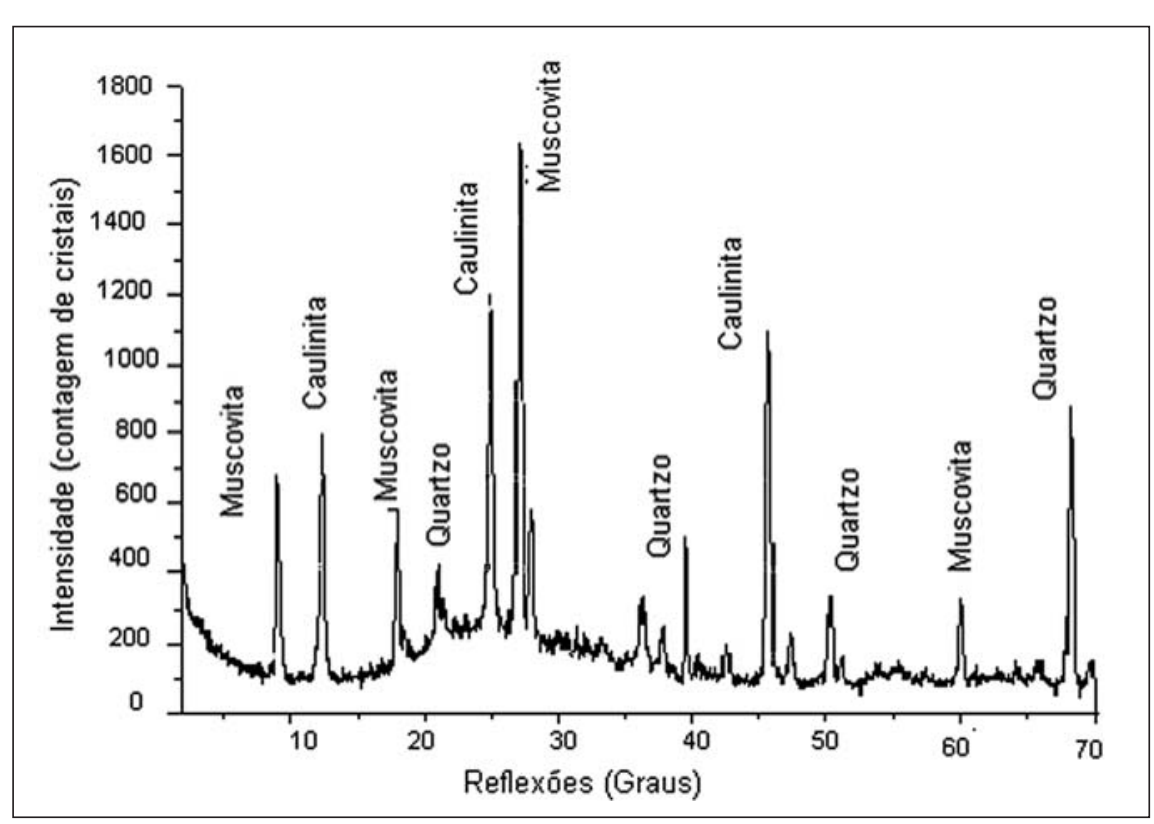

Figura 3 - Difratograma típico para o xisto.

\subsection{Levantamento em campo do escorregamento}

Foi feito o levantamento topográfico de detalhe do escorregamento, que é mostrado na Figura 5. A Figura 5 mostra o escorregamento visto em planta. Na Figura 6, onde o escorregamento é mostrado em perfis, é possível observar a mudança ocorrida na forma inicial do talude, interfe- 
Sueli Batista Ferreira et al.

rindo significativamente com as obras de retaludamento.

O levantamento em campo indicou que o escorregamento não é condicionado por planos de anisotropia do material. No local estudado, os escorregamentos têm características típicas de solos, com formas aproximadamente circulares em perfil, em função de o xisto se encontrar muito intemperizado.Os perfis das rupturas (Figura 6) e as observações de campo permitiram concluir que o escorregamento se deu em várias etapas, levando à formação de várias superfícies de ruptura que se interligaram.

\section{Discussão dos resultados}

Em outros locais da encosta, os movimentos estão associados a planos de anisotropia do material. Próximo ao Centro de Convenções da UFOP, que foi construído na base do Morro do Curral, Bairro Pilar, foram identificados alguns desses escorregamentos, como mostra Fernandes (2000). Também em Pinheiro (2002), que identificou movimentos em área adjacente à estudada por Fernandes, foram descritos movimentos típicos de rochas, condicionados por planos de fraturas e pela superfície de xistosidade.

Já no local analisado nesse trabalho, o efeito do intemperismo químico leva a um condicionamento tanto do material rochoso quanto do tipo de ruptura distintos dos locais já estudados e descritos por Fernandes (2000) e Pinheiro (2002). Assim, a caracterização do material rochoso deve ser feita como se esse material fosse de fato um solo. Ensaios de laboratório para medição de ín-

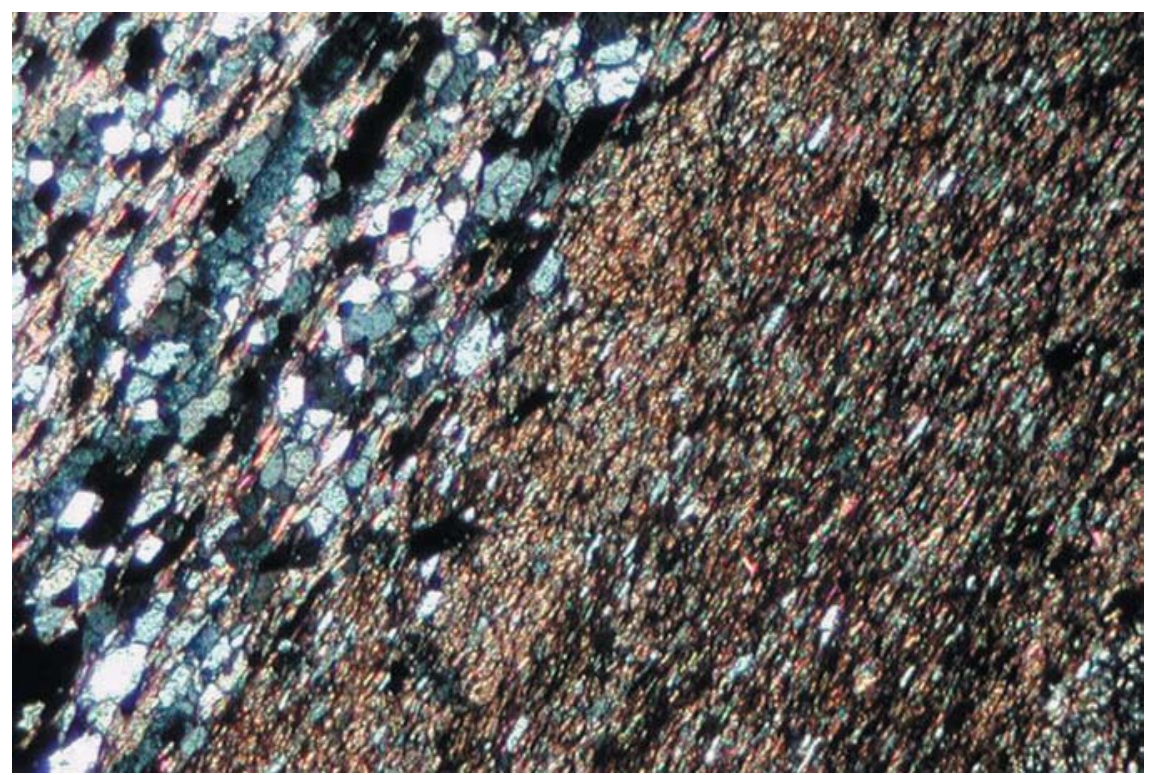

Figura 4 - Contato nível quartzozo com nível de muscovita. Polarizadores cruzados.

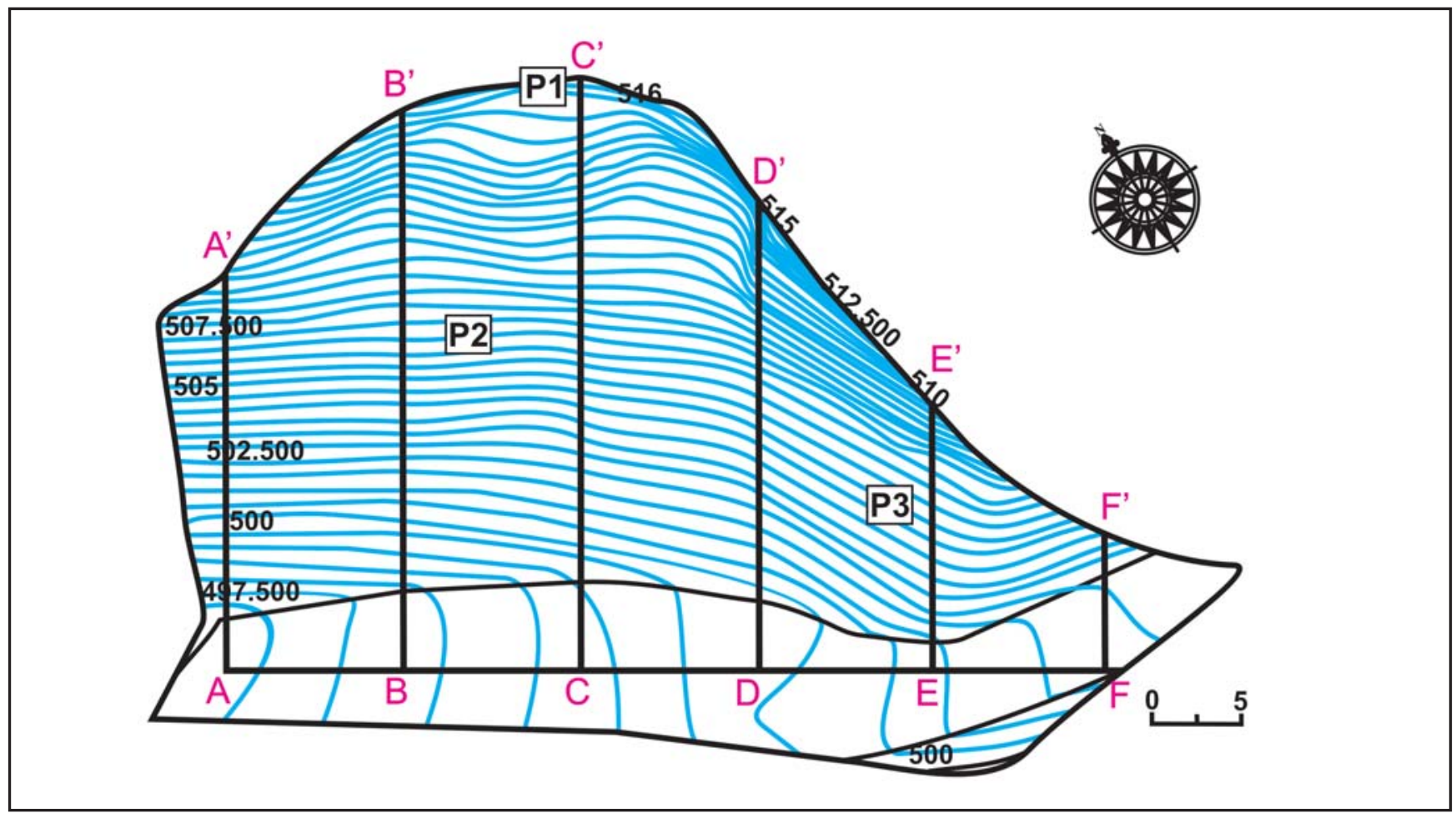

Figura 5 - Mapa topográfico do escorregamento. 

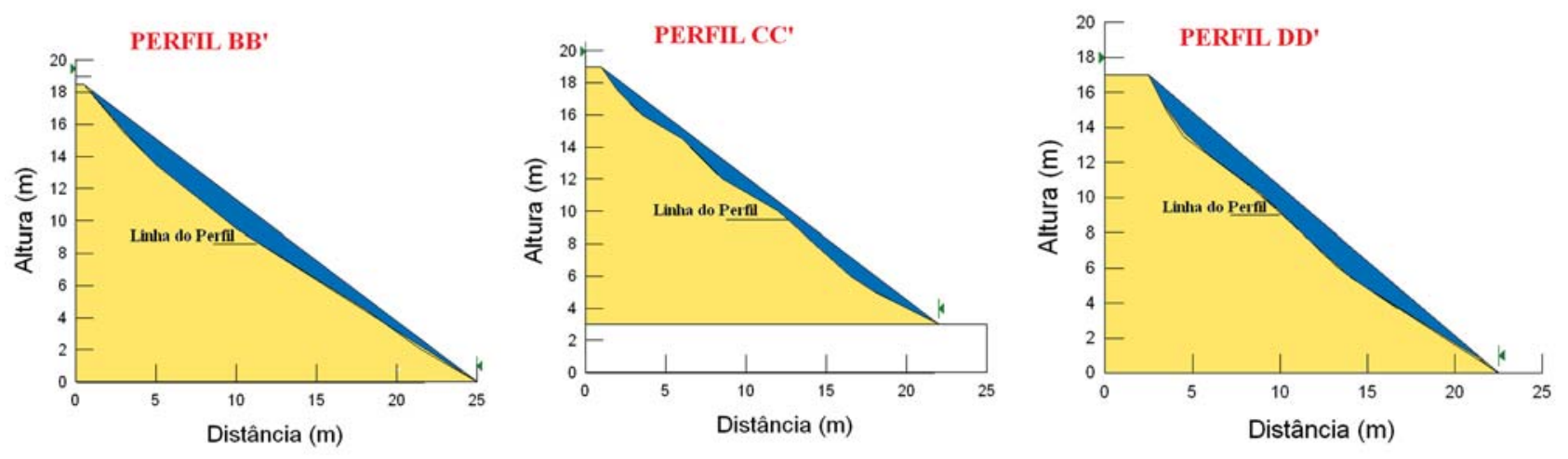

Figura 6 - Perfis do escorregamento.

dices físicos, bem como ensaios de cisalhamento para estimação da resistência do material podem ser realizados, utilizando-se a metodologia já estabelecida para solos.Os cálculos de estabilidade para avaliar a extensão da ruptura e a análise de movimentos futuros também devem levar em conta a metodologia já estabelecida para análise de escorregamentos em solos através, por exemplo, da aplicação de métodos de equilíbriolimite, com a divisão da superfície de ruptura em fatias.

Já nos trabalhos de Fernandes (2000) e Pinheiro (2002), a identificação das rupturas foi feita a partir da utilização de projeções estereográficas, que permitem a análise cinemática de mecanismos de ruptura condicionados por planos de anisotropia do material.

\section{Considerações finais}

A falta de espaços adequados para construção, aliada à ocupação urbana desordenada na cidade de Ouro Preto, vem trazendo graves prejuízos ao planejamento racional do espaço territorial da cidade. A ação antrópica e a ocorrência de intensa precipitação pluviométrica são fatores determinantes nos movimentos em encostas, como bem demonstram os trabalhos realizados sobre os movimentos ocorridos no Morro do Curral.O levantamento desses movimentos e a caracterização do material que constitui as encostas auxiliam a realização de análises de quantificação dos riscos geotécnicos e a proposição de medidas mitigadoras desses movimentos. Levantamentos detalhados em campo da geometria da superfície de ruptura, como o que foi apresentado nesse trabalho, permitem a reconstituição dos movimentos e os fatores causadores dos mesmos.

$\mathrm{Na}$ determinação das causas dos movimentos em encostas é fundamental a caracterização do material que constitui o talude. Rochas brandas, quando submetidas a intenso intemperismo químico, como é comum na região de Ouro Preto, podem apresentar comportamento típico de solos, tanto em relação às características de resistência, quanto à natureza dos movimentos de massa.

\section{Referências bibliográficas}

BONUCCELLI, T. J. Movimentos gravitacionais de massa e processos erosivos com aplicação na área urbana de Ouro Preto, MG - Escala
1:10.000. Escola de Engenharia de São Carlos, Universidade de São Paulo, 1999. 191p. (Tese de Doutorado)

DORR II, J. V. N. Phisiographic, stratigraphic and structural development of the Quadrilatero Ferrifero, Minas Gerais. Brasil, DNPM/USGS. Washington, 1969. 109p.

FERNANDES, G. Caracterização e classificação geomecânica da encosta do morro do Curral Centro de Artes e Convenções de Ouro Preto. CONGRESSO BRASILEIRO DE GEOLOGIA DE ENGENHARIA E AMBIENTAL, 10 . Ouro Preto, 2002, em CD.

FERNANDES, G. Caracterização geológicogeotécnica e proposta de estabilização da encosta do morro do Curral. Centro de Artes e Convençães de Ouro Preto. Universidade Federal de Ouro Preto, 2000. 136p. (Dissertação de Mestrado).

FERREIRA, S. B. Estudo de ruptura em talude urbano no Morro do Curral. Universidade Federal de Ouro Preto, 2004. 87p. (Dissertação de Mestrado).

HUNT, R. E. Geotechnical engineering investigation manual. USA: McGraw-Hill, 1984. 983p.

PINHEIRO, A. L. Análise de rupturas em taludes no morro do Curral. Universidade Federal de Ouro Preto, 2002.116p. (Dissertação de Mestrado).

PINHEIRO, A. L., SOBREIRA, F. G., LANA, M. S. Influência da expansão urbana nos movimentos em encostas na cidade de Ouro Preto, MG. REM - Revista Escola de Minas, v. 56, n.3, p. 169174, 2003.

SOBREIRA, F. G., ARAÚJO, L. G., BONUCCELLI, T. J. Levantamento de soluçães estruturais para a contenção de encostas em Ouro Preto-MG. Ouro Preto. UFOP: 1990.91p.

Artigo recebido em 22/03/2004 e aprovado em 05/11/2004.

\section{REM - Revista Escola de Minas}

\section{www.rem.com.br www.scielo.br}

